\title{
Asymmetric Oxidative Cation/Olefin Cyclization of Polyenes: Evidence for Reversible Cascade Cyclization ${ }^{* *}$
}

\author{
Charles A. Mullen, Alison N. Campbell, and Michel R. Gagné* \\ Department of Chemistry, University of North Carolina at Chapel Hill, Chapel Hill, NC 27599- \\ 3290 (USA)
}

\section{Keywords}

asymmetric synthesis; cyclization; platinum; reaction mechanisms

\begin{abstract}
The biosynthesis of cyclic terpenes from polyene precursors by cyclase enzymes is one of nature's most elegant chemical transformations.[1] The ease with which nature creates complex molecular architectures from achiral precursors has motivated efforts to develop similarly powerful synthetic methodologies.[2] Alimited number of asymmetric methods have been developed,[3] including the notable Brønsted/Lewis acid (BLA) cascade reactions developed by Yamamoto and co-workers, [4] and the recent halocyclization of polyprenoids reported by Ishihara and co-workers.[5] We recently reported a regio- and diastereoselective oxidative polycyclization of di- and trienols catalyzed by achiral [(dppe)Pt] dications, wherein turnover was achieved by the trityl cation abstracting a hydride from a putative $\left[(\text { dppe)Pt-H }]^{+}\right.$intermediate (Scheme 1).[6,7] Since there are so few asymmetric methods for such cascade cyclizations, [8] we initiated efforts to render this initial discovery into an oxidative method that was regio-,[9] stereo-, and enantioselective.[10,11] In the course of discovering and then subsequently mechanistically examining such an enantioselective variant, we have also made the surprising observation that the initial cascade cyclization is not necessarily the stereochemistry-determining step.
\end{abstract}

A wide variety of readily available chiral diphosphine ligands for the conversion of $\mathbf{1}$ into $\mathbf{2}$ were screened to find the optimal combination of catalyst and conditions for the transformation (Table 1). In general the results with the standard array of chiral diphosphine ligands (binap, MeO-biphep, etc.) were disappointing. Additional substitution on the aryl ring of the $\mathrm{P}$ atom, however, gave noticeable improvements in the selectivities (Table 1, entry 3 versus 1 and entry 5 versus 4). Ligands that had larger groups at the 3,5-positions of the ring did not turnover (Table 1, entries 6 and 8; dtbm = 3,5-ditbutyl-4-methoxy). Moderate enantioselectivites were also observed with the bicp and bdpp chiral bisphosphine ligands, and the best ligand was xylyl-phanephos (3); the catalyst derived from halide abstraction from [(xylyl-phanephos) $\left.\mathrm{PtCl}_{2}\right]\left(\left[(3) \mathrm{PtCl}_{2}\right]\right)$ yielded $\mathbf{2}$ in $75 \%$ ee.

\footnotetext{
** The authors thank the National Institutes of Health, General Medicine for generous support (Grant GM-60578). (c) 2008 Wiley-VCH Verlag GmbH amp; Co. KGaA, Weinheim Fax: (+ 1) 919-962-6342, mgagne@unc.edu. Supporting information for this article is available on the WWW under http://www.angewandte.org or from the author.
} 


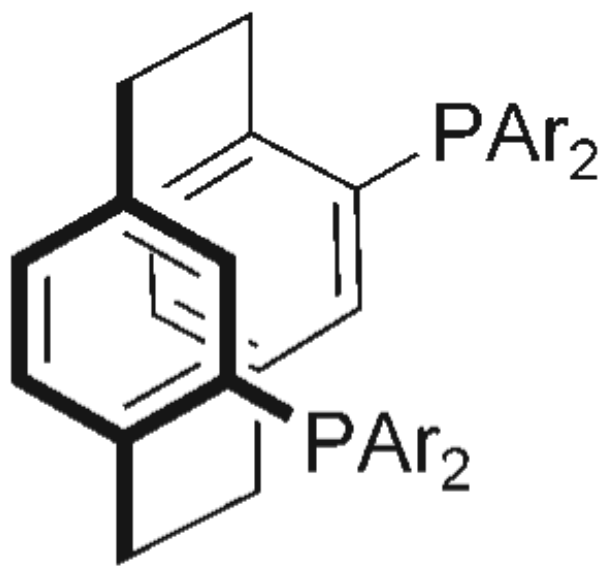

\section{$\mathrm{Ar}=3,5-\mathrm{Me}_{2} \mathrm{C}_{6} \mathrm{H}_{4}$ (S)-xylyl-phanephos}

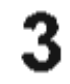

Solvents and counterions were examined to additionally improve the system. Of the series of counterions, $\mathrm{BF}_{4}^{-}, \mathrm{SbF}_{6}{ }^{-}, \mathrm{NTf}_{2}{ }^{-}, \mathrm{OTf}^{-}$, and $\mathrm{F}_{3} \mathrm{CCO}_{2}{ }^{-}, \mathrm{BF}_{4}{ }^{-}$gave the highest enantioselectivity without affecting the product yield. The $\mathrm{OTf}^{-}$counterion exhibited a slight increase in the enantioselectivity of the reaction, but acid-catalyzed products dominated the reaction mixture. With regard to solvent choice, it had been previously shown that highly polar nitro-containing solvents (i.e. nitromethane) were crucial for achieving good yields and high reaction rates in the $\left[\mathrm{Pt}^{2+}\right]$-mediated olefin cyclizations.[12] For this reason, nitromethane $(70 \% e e)$, nitroethane $(75 \% e e)$, 1-nitropropane $(74 \% e e)$, and 2nitropropane $(71 \%$ ee $)$ were screened as possible solvents for the enantioselective synthesis of 2 with [(3) $\mathrm{Pt}^{2+}$. All solvents led to comparable rates, but nitroethane was optimal with respect to the enantioselectivity. In the case of volatile products, nitromethane was preferable because the product could be extracted into pentane.

The optimum catalyst was applied to a collection of dienol and trienol substrates (Table 2). The reaction was compatible with monosubstitution and 1,2-disubstitution at the terminal alkene, however, $Z$ alkenes were better behaved than the $E$ alkenes. This sensitivity to alkene stereochemistry was not previously observed in the achiral dppe catalysts, and like the chiral catalyst, a trisubstituted terminal alkene was not tolerated (not shown). In each case a single stereo- and regioisomer of the product was obtained. Although perfect stereospecificity was observed in the $E$ and $Z$ substrates (Table 2, entries 4 versus 5), they markedly differed in their enantioselectivities; the terminal $Z$ alkene (Table 2, entry 5) cyclized with the highest selectivities (up to $87 \%$ ee), non-substituted terminal alkenes provided moderate to good selectivities (Table 2, entries 1, 2, and 6), and terminal $E$ alkenes had poor selectivities (Table 2, entries 3 and 4). The absolute stereochemistry of $\mathbf{1 3}$ was determined by using hydrogenation to give known $\mathbf{1 3}-\mathbf{H}_{2}$, the optical rotation of which was compared to reported values.[13] The stereochemistry of the remaining compounds in Table 2 were assigned by analogy.

Intrigued by the markedly different results for the xylyl-phanephos ligand, we obtained an $\mathrm{X}$-ray crystallographic structure of the catalyst precursor (Figure 1).[14,15] Except for a 
particularly broad bite angle $\left(103.75^{\circ}\right)$, there is surprisingly little quadrant differentiation, which is normally observed in highly selective ligands like binap.

In situ monitoring of [(binap) $\left.\mathrm{Pt}^{2+}\right]$ - and [(xylyl-binap) $\left.\mathrm{Pt}^{2+}\right]$-catalyzed reactions indicated, from $J_{\mathrm{Pt}-\mathrm{P}}$ coupling constants[16] and ${ }^{19} \mathrm{~F}$ NMR data, that the catalyst rested as an alkylnitrile species. Unfortunately the reactions run with xylyl-phanephos resulted in a complex multicomponent mixture ( ${ }^{31} \mathrm{P}$ NMR spectra). The alkyl-nitrile species, for both xylyl-MeObiphep and xylyl-binap, were observed as a mixture of two isomers in a ratio of $1.8: 1{ }^{31} \mathrm{P}$ NMR methods) - solutions of these species could be generated at $0^{\circ} \mathrm{C}$, where they were stable to $\beta$-hydride elimination.<smiles>C[P+]=P</smiles><smiles>[B][P+]1=CC2C1CC[C@@]1(C)Oc3ccccc3CC21</smiles>

For one of these solutions, the benzopyran complex was cleaved from the Pt with $\mathrm{NaBH}_{4}$ to yield reduced compound $\mathbf{2}-\mathbf{H}_{\mathbf{2}}$ with an enantiomeric ratio (e.r.) that was identical to the d.r. of the alkyl-nitrile species (Scheme 2); thus the two isomers appeared to be a matched and mismatched combination of the trans ring junction and the ligand chirality. Surprisingly, the d.r. value of the alkyl-nitrile species (or the e.r. value of $\mathbf{2}-\mathbf{H}_{\mathbf{2}}$ ) was lower than the e.r. value for the catalytic reaction $(2.85: 1)$.

The alkyl-nitrile intermediate (d.r. $=1.8: 1)$ was next generated in situ $\left(0^{\circ} \mathrm{C}\right)$ under single turnover conditions (only the trityl cation was missing). When this reaction mixture was warmed to room temperature and allowed to undergo elimination to give products, the alkene products were obtained with an e.r. value (2.6:1) that nearly matched the value obtained under normal catalysis conditions (e.r. $=2.85: 1$ ), and contrasted with value determined in the $\mathrm{NaBH}_{4}$ cleavage studies (e.r. = 1.8:1) (Scheme 2). When the alkyl-nitrile intermediate was prepared as described above $\left(0^{\circ} \mathrm{C}\right)$ and separated from acidic species $\mathrm{Ph}_{2} \mathrm{NH}_{2}{ }^{+}$, which results from phenol trapping, the alkene was not formed with the e.r. value found under catalytic conditions $(2.85: 1)$, but rather with an e.r. value that matched the d.r. value of the alkyl-nitrile intermediate (1.8:1). These observations are inconsistent with an irreversible, stereochemistry-determining cascade cyclization, and suggested that $\mathrm{Ph}_{2} \mathrm{NH}_{2}{ }^{+}$ mediates a proton-coupled retrocyclization (Scheme 3).[17,18]

Although there are several candidate steps for the stereochemistry-determining event[19] the counterintuitive notion of an electrophilic cascade not being stereochemistry-determining is intriguing and will have important consequences in future efforts to improve such catalysts.

To summarize, we report herein an addition to the short list of catalysts that mediate an enantioselective cation/olefin cascade cyclization of polyprenoids. Unlike the chiral acids (Yamamoto's BLA's) and the chiral iodonium salts' (Ishihara's $\mathrm{R}_{3} \mathrm{P}^{-} \mathrm{I}^{+}$), this platinum catalyst mediates a stereospecific oxidative transformation, which works optimally on mono-substituted or terminal Z-disubstituted alkenes, and enables enantio- and regioselective access to structures that are not otherwise available.

\section{Experimental Section}

Typical polycyclizaton procedure: 2.2 equiv $\mathrm{AgBF}_{4}$ was added to a $13.3 \mathrm{~mm}$ solution of [(3) $\mathrm{PtCl}_{2}$ ] (typically $0.02 \mathrm{mmol}$ ) in $\mathrm{EtNO}_{2}$. The reaction mixture was stirred for $1 \mathrm{~h}$ in the dark and then 21.0 equiv $\mathrm{Ph}_{3} \mathrm{COMe}$ on polystyrene resin and 10 equiv substrate were added. The reaction mixture was stirred at room temperature in the dark until the reaction was 
complete by GC analysis (typically $6-14 \mathrm{~h}$ ). The reaction mixture was then quenched by passage through a plug of silica gel and eluted with ether. The solvent was then removed in vacuo and the residue was purified by column chromatography. The enantiomeric excess was determined by chiral stationary phase gas chromatographic analysis using an Agilent Cyclosil column. In the case of volatile substrate $\mathbf{4}$, nitromethane was used and $\mathbf{5}$ was isolated by first extracting into pentane under biphasic conditions.

Preparation of alkyl-nitrile intermediate: In a nitrogen filled glove box either [(xylylbinap)PtI 2 or [(xylyl-MeO-biphep)PtI 2 ( $0.035 \mathrm{mmol}), \mathrm{AgBF}_{4}(0.087 \mathrm{mmol})$, and $\mathrm{NCC}_{6} \mathrm{~F}_{5}$ $(0.105 \mathrm{mmol})$ were stirred in $\mathrm{CD}_{3} \mathrm{NO}_{2}$ for $1 \mathrm{~h}$. AgI was removed by filtration through a PTFE filter. The solution was then cooled to $-78^{\circ} \mathrm{C}$ and $\mathbf{1}(0.070 \mathrm{mmol})$ and $\mathrm{Ph}_{2} \mathrm{NH}(0.070$ $\mathrm{mmol}$ ) were added to the reaction mixture. The reaction mixture was warmed to $0^{\circ} \mathrm{C}$ overnight after which the alkyl-nitrile intermediate was observed by ${ }^{31} \mathrm{P}$ NMR spectroscopy.

\section{Supplementary Material}

Refer to Web version on PubMed Central for supplementary material.

\section{References}

[1]. a) Yoder RA, Johnston JN. Chem. Rev 2005;105:4730-4756. [PubMed: 16351060] b) Wendt KU, Schulz GE, Corey EJ, Liu DR. Angew. Chem 2000;112:2930-2952.Angew. Chem. Int. Ed 2000;39:2812-2833. c) Abe I, Rhomer M, Prestwich GD. Chem. Rev 1993;93:2189-2206.

[2]. See reference [1a] Nicolaou KC, Edmonds DJ, Bulger PG. Angew. Chem 2006;118:7292-7344. Angew. Chem. Int. Ed 2006;45:7134-7186. and also, for example, Kurdyumov AV, Hsung RP. J. Am. Chem. Soc 2006;128:6272-6273. [PubMed: 16683764]

[3]. Sakakura A, Ishihara K. Chem. Today 2007;25:9-12.

[4]. a) Ishibashi H, Ishihara K, Yamamoto H. J. Am. Chem. Soc 2004;126:11122-11123. [PubMed: 15355072] b) Kumazawa K, Ishihara K, Yamamoto H. Org. Lett 2004;6:2551-2554. [PubMed: 15255688] Grütter C, Alonso E, Chougnet A, Woggon W-D. Angew. Chem 2006;118:11441148.Angew. Chem. Int. Ed 2006;45:1126-1130.

[5]. Sakakura A, Ukai A, Ishihara K. Nature 2007;445:900-903. [PubMed: 17314976]

[6]. Mullen CA, Gagné MR. J. Am. Chem. Soc 2007;129:11880-11881. [PubMed: 17850150]

[7]. For recent reviews on electrophilic Pt catalysts, see: a) Chianese AR, Lee SJ, Gagné MR. Angew. Chem 2007;119:4118-4136. Angew. Chem. Int. Ed 2007;46:4042-4059. b) Fürstner A, Davies PW. Angew. Chem 2007;119:3478-3519. Angew. Chem. Int. Ed 2007;46:3410-3449.

[8]. For a recent intermolecular initiation of an electrophilic cyclization by a chiral oxonium ion, see: Zhao Y-J, Chng S-S, Loh T-P. J. Am. Chem. Soc 2007;129:492-493. [PubMed: 17227003]

[9]. For a Pd-catalyzed, non-regioselective version of this reaction, see: Koh JH, Mascarenhas C, Gagné MR. Tetrahedron 2004;60:7405-7410.

[10]. For recent cases of enantioselective electrophilic $\mathrm{C}=\mathrm{C}$ activation by metal catalysts, see: a) Zhang Y, Sigman MS. J. Am. Chem. Soc 2007;129:3076-3077. [PubMed: 17298071] b) Watson MP, Overman LE, Bergman RG. J. Am. Chem. Soc 2007;129:5031-5044. [PubMed: 17402733] c) LaLonde RL, Sherry BD, Kang EJ, Toste FD. J. Am. Chem. Soc 2007;129:2452-2453. [PubMed: 17290999] d) Zhang Z, Widenhoefer RA. Angew. Chem 2007;119:287-289. Angew. Chem. Int. Ed 2007;46:283-285. e) Zhang Z, Bender CF, Widenhoefer RA. J. Am. Chem. Soc 2007;129:14148-14149. [PubMed: 17967025] f) Liu C, Widenhoefer RA. Org. Lett 2007;9:1935-1938. [PubMed: 17428061] g) Han X, Widenhoefer RA. Org. Lett 2006;8:38013804. [PubMed: 16898821] h) Feducia JA, Campbell AN, Doherty MQ. J. Am. Chem. Soc 2006;128:13290-13297. [PubMed: 17017811] i) Trend RM, Ramtohul YK, Stoltz BM. J. Am. Chem. Soc 2005;127:17778-17788. [PubMed: 16351107]

[11]. For cases of chiral $\mathrm{I}^{+}, \mathrm{Hg}^{2+}$, and $\mathrm{R}^{*} \mathrm{Se}^{+}$alkene activations, see: a) Kang SH, Lee SB, Park CM. J. Am. Chem. Soc 2003;125:15748-15749. [PubMed: 14677957] b) Haas J, Piguel S, Wirth T.

Angew Chem Int Ed Engl. Author manuscript; available in PMC 2010 July 23. 
Org. Lett 2002;4:297-300. [PubMed: 11796074] c) Kitagawa O, Taguchi T. Synlett 1999:11911199. d) Kang SH, Kim M. J. Am. Chem. Soc 2003;125:4684-4685. [PubMed: 12696867] and references therein; e) Back TG, Dyck BP, Nan S. Tetrahedron 1999;55:3191-3208.

[12]. a) Hahn C, Cucciolito ME, Vitagliano A. J. Am. Chem. Soc 2002;124:9038-9039. [PubMed: 12148993] b) Cucciolito ME, D'Amora A, Vitagliano A. Organometallics 2005;24:3359-3361. c) Cucciolito ME, Amora AD, Tuzi A, Vitagliano A. Organometallics 2007;26:5216-5223. d) Kerber WD, Gagné MR. Org. Lett 2005;7:3379-3381. [PubMed: 16018665]

[13]. Ohloff G, Giersch W, Pickenhagen W, Furrer A, Frei B. Helv. Chim. Acta 1985;68:2022-2029.

[14]. CCDC 684924 contains the supplementary crystallographic data for this paper. These data can be obtained free of charge from The Cambridge Crystallographic Data Centre via www.ccdc.cam.ac.uk/data_request/cif.

[15]. Crystal data for [(3) $\mathrm{PtCl}_{2}$ ] at $296 \mathrm{~K}: \mathrm{C}_{48} \mathrm{H}_{50} \mathrm{Cl}_{2} \mathrm{P}_{2} \mathrm{Pt}, M_{\mathrm{r}}=954.81 \mathrm{~g} \mathrm{~mol}^{-1}$, triclinic, $P 1^{-}, a=$ $10.9793(6), b=14.7178(8), c=17.5110(9), V=2586.6(2) \AA^{3}, Z=2, \rho_{\text {cald }}=1.226 \mathrm{mg} \mathrm{m}^{-3}, R_{1}$ $=0.0301, w R_{2}=0.0779, \mathrm{GOF}=1.079$.

[16]. a) Spencer JL, Mhinzi GS. J. Chem. Soc. Dalton Trans 1995:3819-3824. b) Mole L, Spencer JL, Carr N, Orpen AG. Organometallics 1991;10:49-52.

[17]. We have recently documented a number of $\left[\mathrm{P}_{3} \mathrm{Pt}^{2+}\right]$-mediated reversible cascade cyclizations. See: Feducia JA, Gagné MR. J. Am. Chem. Soc 2008;130:592-599. [PubMed: 18095679]

[18]. Microscopic reversibility arguments suggest that the retrocyclization would also be L-dependent, where $\mathrm{L}$ is solvent or substrate.

[19]. The possibilities include $\beta$-hydride elimination, hydride abstraction of an olefin hydride intermediate, or alkene displacement of an olefin from the olefin hydride intermediate. 


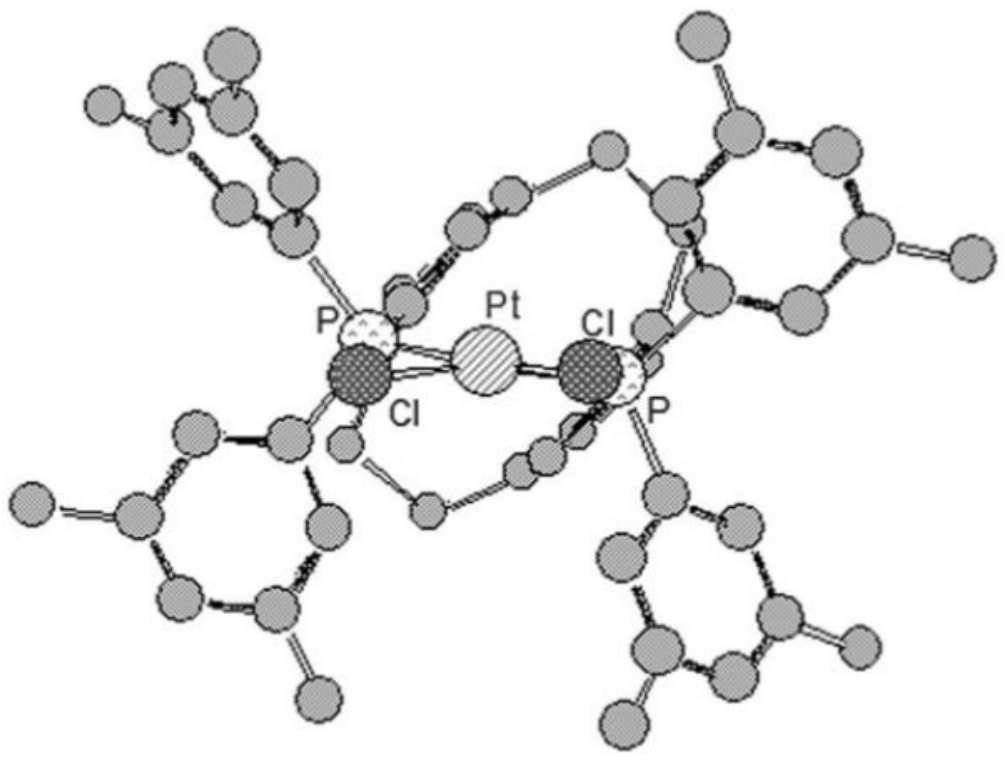

Figure 1.

X-ray crystallographic structure of $\left[(3) \mathrm{PtCl}_{2}\right]$. Bond angles include P-Pt-P $\left(103.75^{\circ}\right)$, average $\mathrm{P}-\mathrm{Pt}-\mathrm{Cl}\left(85.00^{\circ}\right)$, and $\mathrm{Cl}-\mathrm{Pt}-\mathrm{Cl}\left(87.58^{\circ}\right)$. 


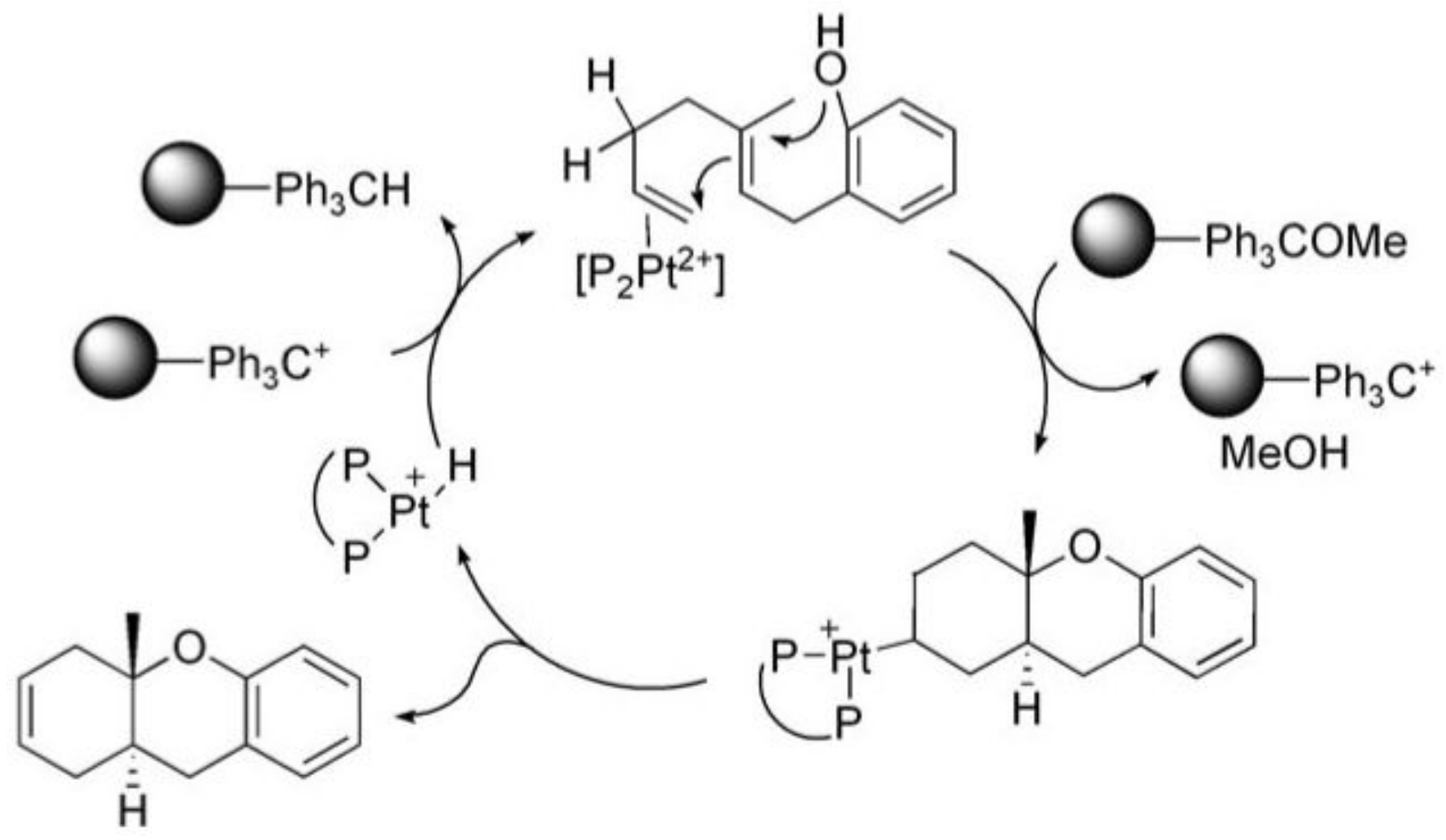

Scheme 1.

Proposed catalytic cycle for $\left[\mathrm{P}_{2} \mathrm{Pt}^{2+}\right]$-catalyzed polycyclization. 


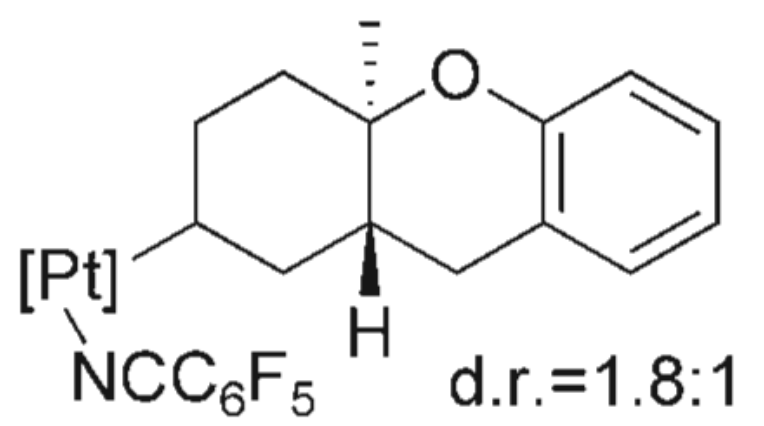<smiles>C[C@]1(O)CCCCC1C#N</smiles>
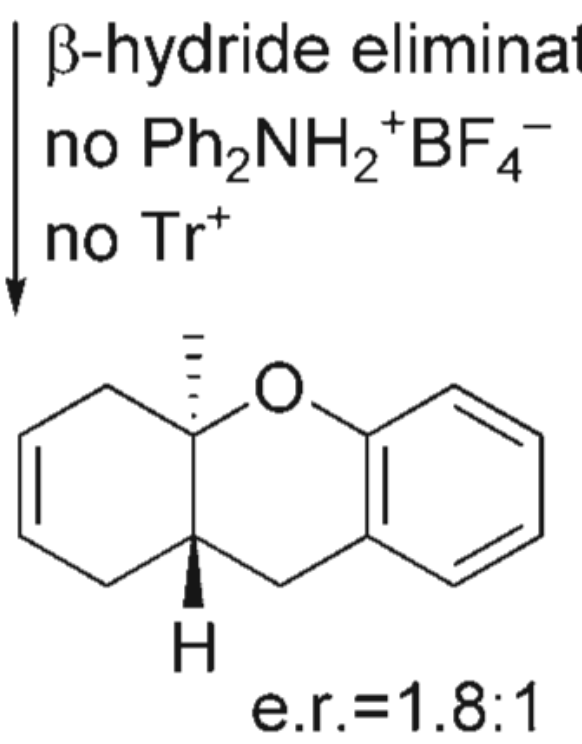

$\beta$-hydride elimination with $\mathrm{Ph}_{2} \mathrm{NH}_{2}{ }^{+} \mathrm{BF}_{4}^{-}$ no $\mathrm{Tr}^{+}$

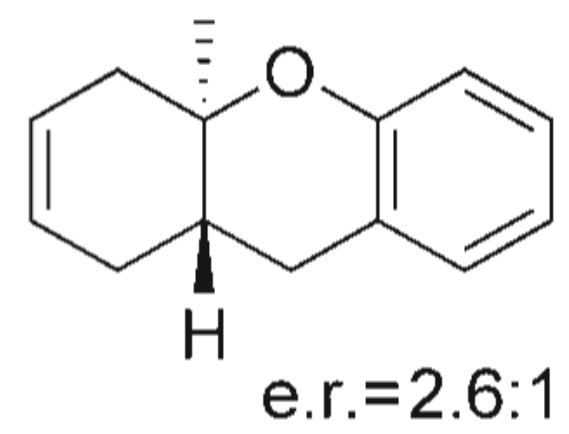

Scheme 2.

Stoichiometric reactivity of the alkyl-nitrile resting state. 

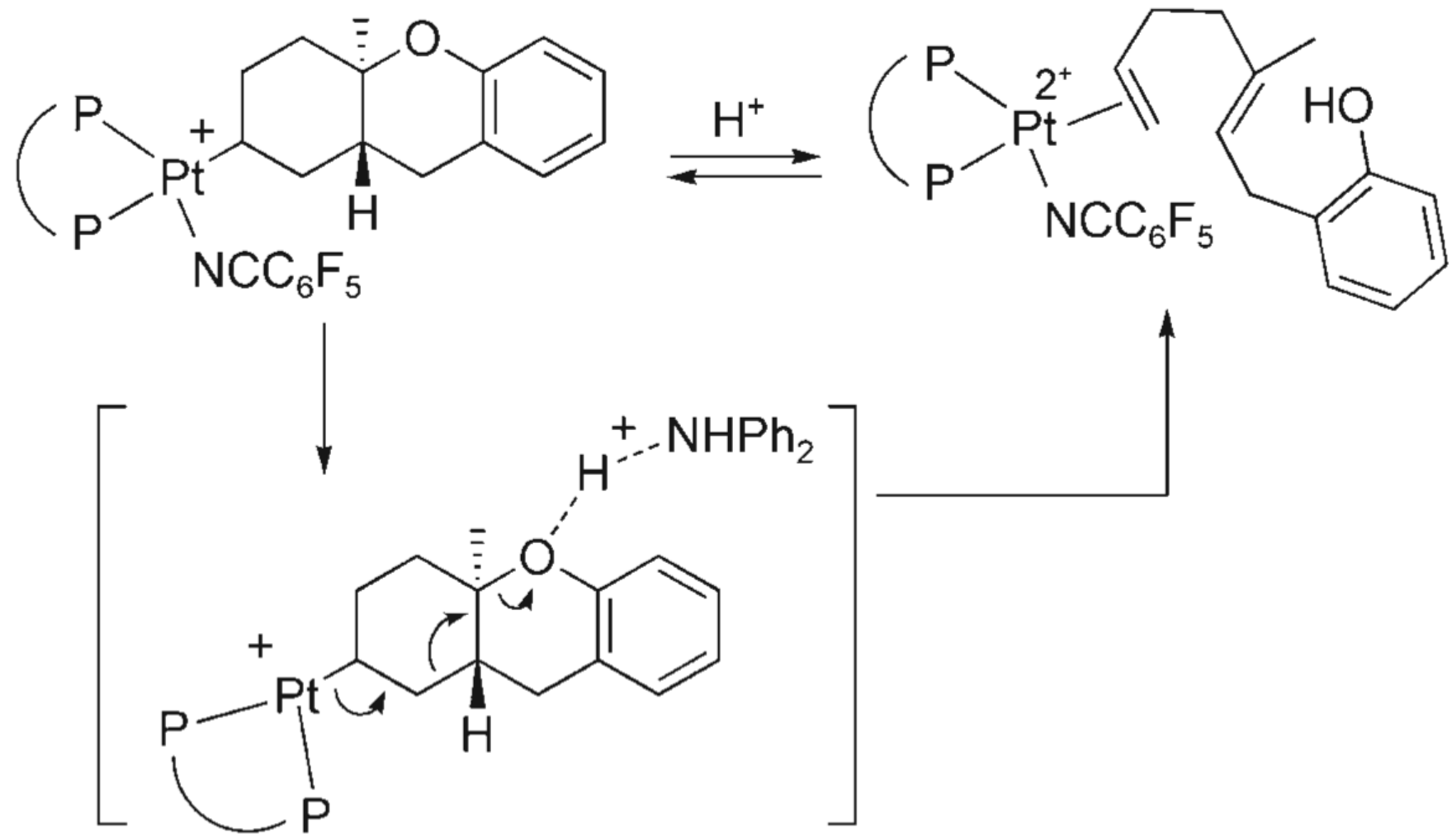

Scheme 3.

Proton-coupled retrocyclization. 
Table 1

Representative screen of diphosphine ligands for $\left[\mathrm{Pt}^{2+}\right]$-catalyzed polycyclization ${ }^{[a]}$

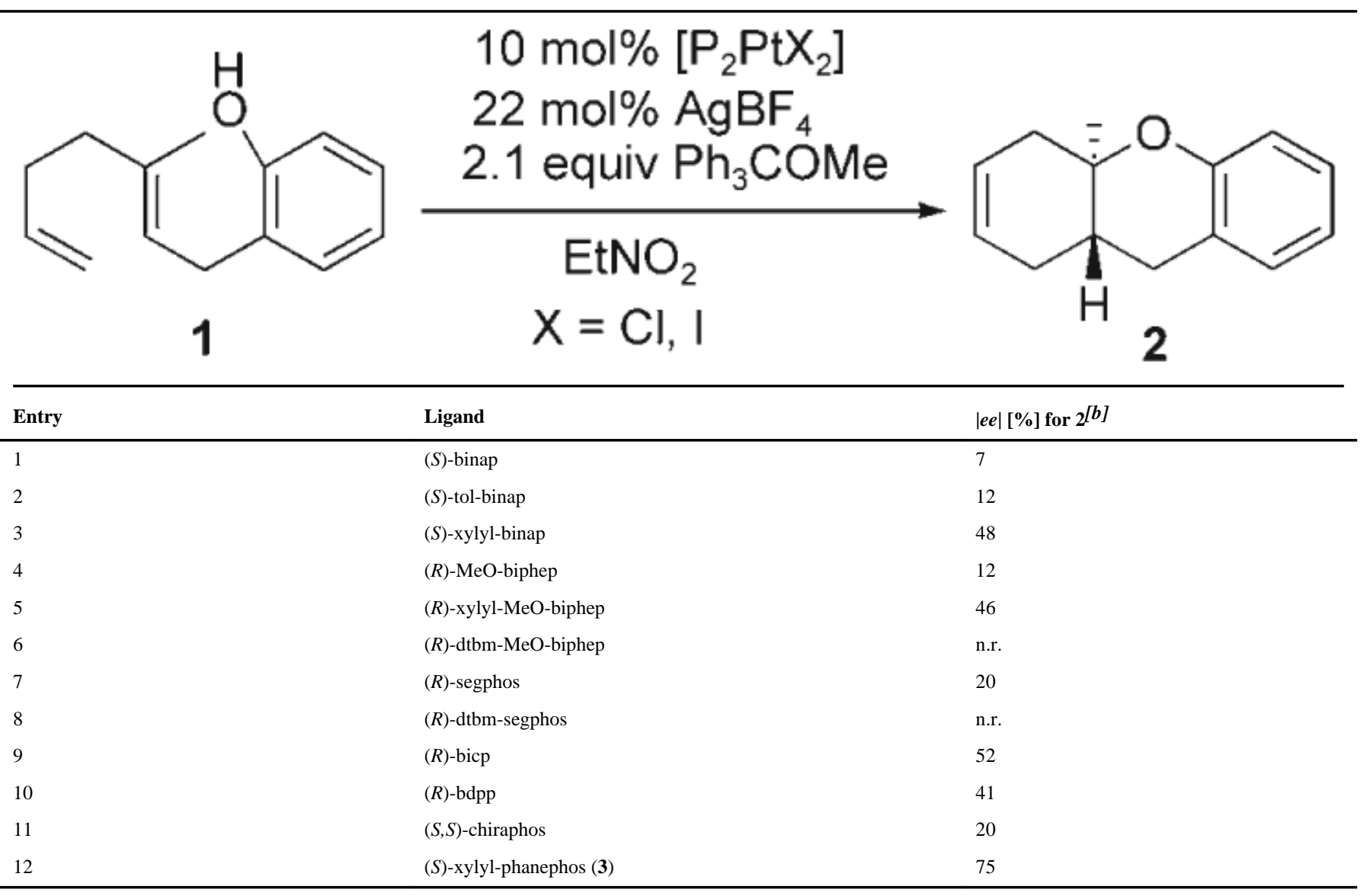

${ }^{[a]}$ Conditions: $10 \mathrm{~mol} \%$ [ $\left.\mathrm{P}_{2} \mathrm{PtX} 2\right]\left(\mathrm{X}=\mathrm{Cl}\right.$ or I), $22 \mathrm{~mol} \% \mathrm{AgBF}_{4}, 2.1$ equiv $\mathrm{Ph}_{3} \mathrm{COMe}$, and $\mathrm{EtNO}_{2}$.

${ }^{[b]}$ Determined by GC analysis. binap=(1,1'-binaphthalene)-2,2'-diylbis (diphenylphosphine); biphep =2,2'-bis (di-phenylphosphanyl)biphenyl; segphos=4,4'-bi-1,3-benzodioxole-5,5'-diyl)bis(diphenylphosphine; bicp = 2,2'-bis(diphenylphosphanyl)dicyclo-pentane; bdpp = 2,4-

bis(diphenylphosphino)pentane; chiraphos = 2,3-bis(diphenylphosphano)butane; phanephos = 4,12-bis(diphenylphosphanyl)-[2,2]paracyclophane; n.r. $=$ no reaction. 


\section{Table 2}

Asymmetric polycyclizations catalyzed by $\left[((S)\right.$-xylyl-phanephos) $\mathrm{Pt}]\left(\mathrm{BF}_{4}\right)_{2} \cdot\left[{ }^{[a],[b]}\right]$

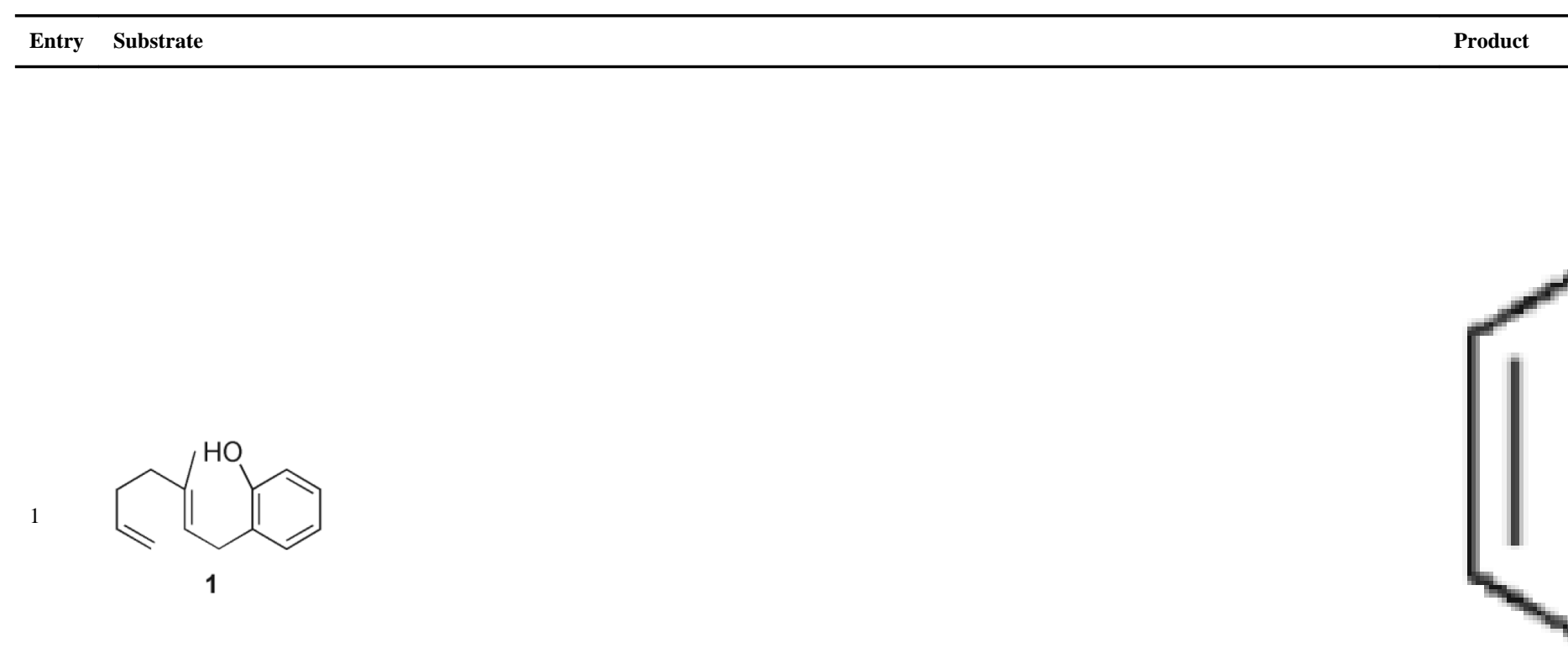


Entry Substrate

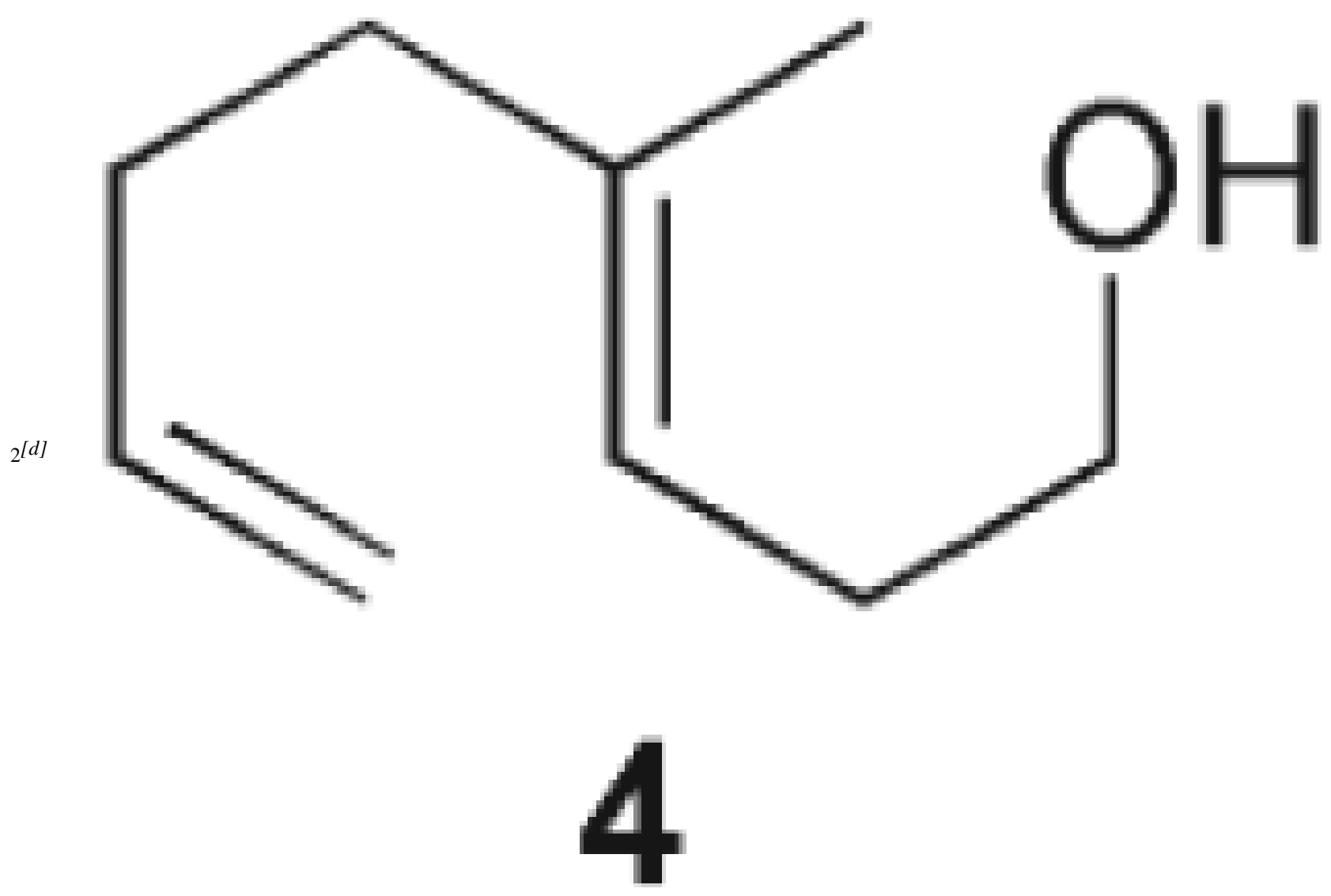

Product

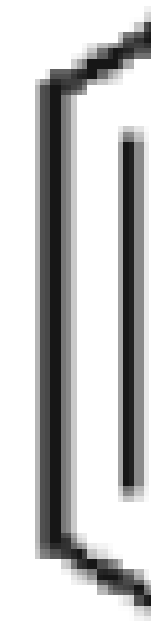




\begin{tabular}{llc}
\hline Entry & Substrate & Product
\end{tabular}
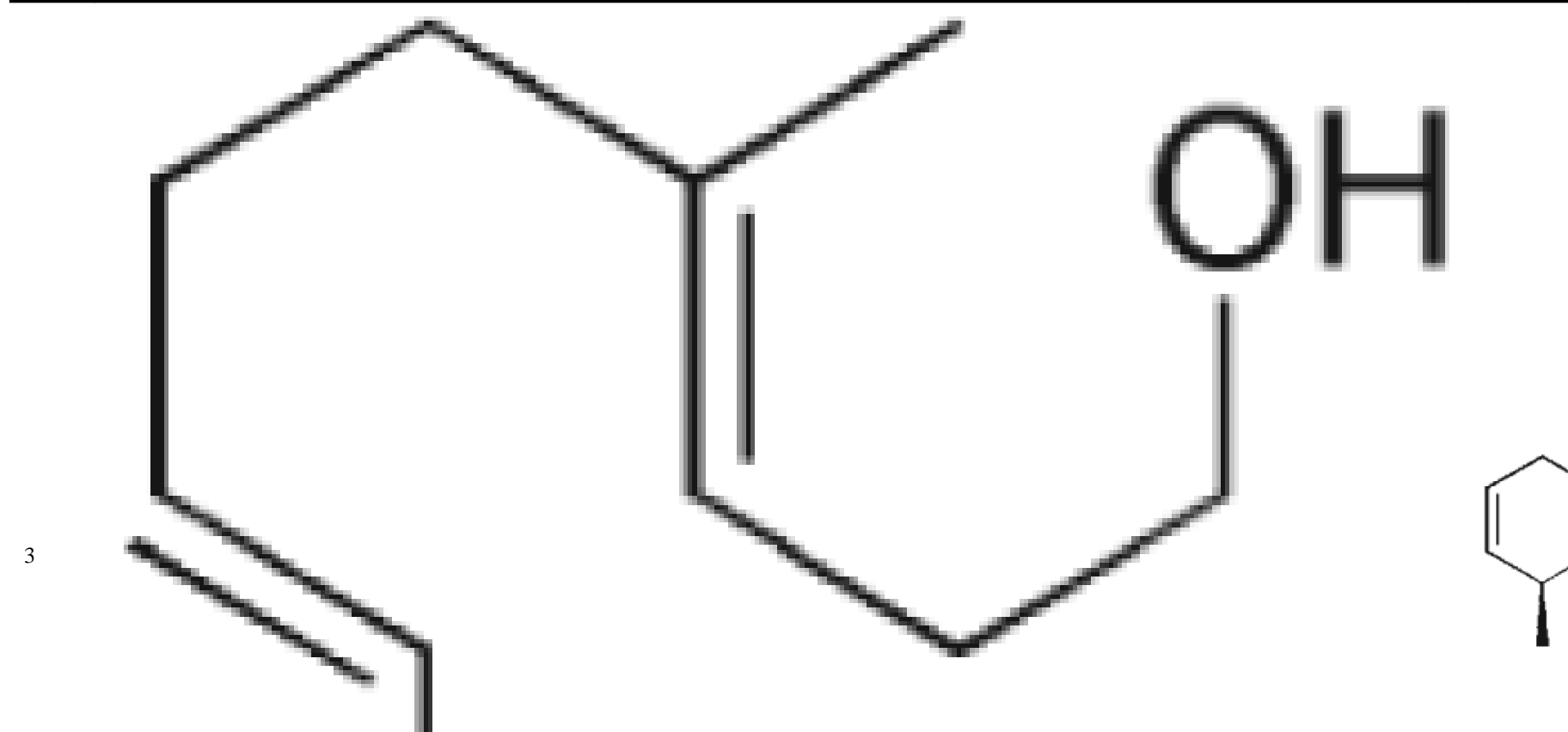

3

$\sqrt{1}$

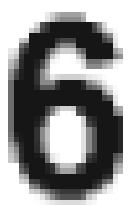

Angew Chem Int Ed Engl. Author manuscript; available in PMC 2010 July 23. 


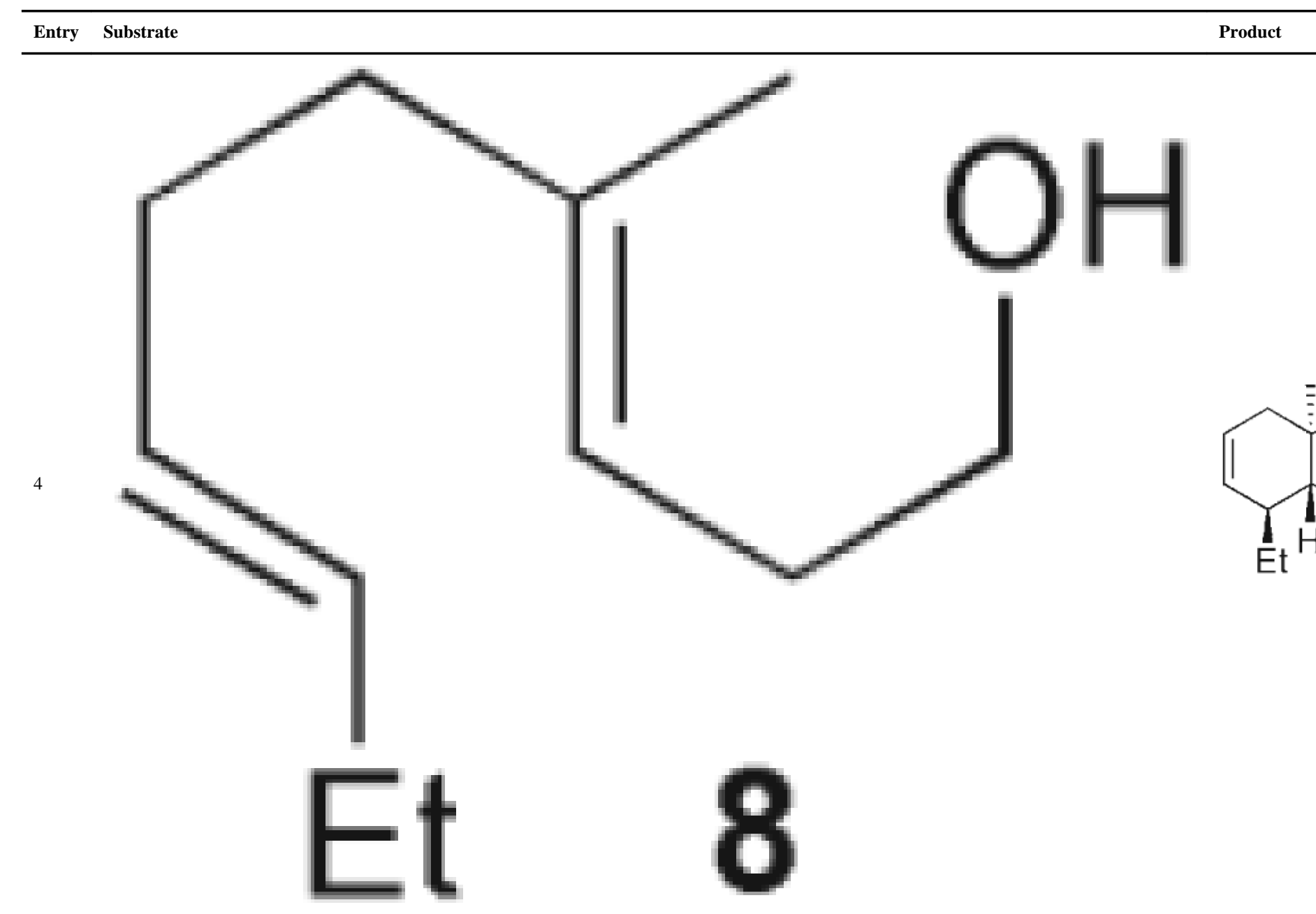


Entry Substrate<smiles>CC1=C(CO)CCC=C1</smiles>

10
Product

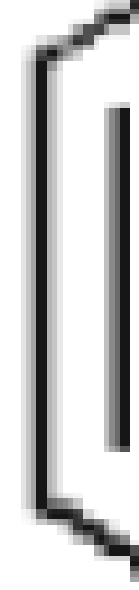

Angew Chem Int Ed Engl. Author manuscript; available in PMC 2010 July 23. 
6<smiles>C=CCCC(C)=CCCCO</smiles>

${ }^{[a]}$ All absolute configurations were assigned by analogy to the known hydrogenated product of $\mathbf{1 3}$. For poorly selective reactions this assignment should be interpreted cautiously.

${ }^{[b]}$ Conditions: $10 \mathrm{~mol} \%$ 3, $22 \mathrm{~mol} \% \mathrm{AgBF}_{4}, 2.1$ equiv $\mathrm{Ph}_{3} \mathrm{COMe}$ (resin), EtNO2, RT.

${ }^{[c]}$ Yield of isolated product.

${ }^{[d]}$ Solvent was $\mathrm{MeNO}_{2}$.

${ }^{[e]}$ Determined after hydrogenation of product. n.d. $=$ not determined . 